\title{
Cases of management of paediatric tubo-ovarian torsion
}

\author{
Ruchi Bhandari*, Manju Khemani, Asif Mustafa
}

Department of Obstetrics and Gynecology, Max Smart Super Speciality Hospital, Saket, New Delhi, India

Received: 15 March 2019

Revised: 30 May 2019

Accepted: 13 June 2019

\section{*Correspondence:}

Dr. Ruchi Bhandari,

E-mail: ruchi.bhandari@yahoo.com

Copyright: $\odot$ the author(s), publisher and licensee Medip Academy. This is an open-access article distributed under the terms of the Creative Commons Attribution Non-Commercial License, which permits unrestricted non-commercial use, distribution, and reproduction in any medium, provided the original work is properly cited.

\begin{abstract}
Ovarian torsion is the fifth most common cause of gynaecologic surgical emergency. It warrants early diagnosis as timely surgical management will avoid the further adnexal injury. In paediatric population, this is especially dangerous as the condition can go undiagnosed because of its rarity and nonspecific presentation. This leads to delay in surgical exploration and loss of ovarian function. In these cases, the ovary and often the ipsilateral fallopian tube twist with the vascular pedicle, resulting in vascular compromise. Unrelieved torsion leads to haemorrhagic infarction. We encountered 3 cases of ovarian torsion in paediatric age group during a period of 12 months. All cases presented with acute pain abdomen for 3-7 days period with loss of appetite and unable to pass motion with varied disappearance of pain. On ultrasound all the cases were diagnosed with ovarian cyst with torsion and underwent laparoscopic cystectomy. This case series is written just to show the results of de-torsion and conserving the fallopian tube and ovary after vascular damage. This type of conservative management may give chance to ovary to return to viability. This was seen in all 3 cases dealt by us on repeat scan on follow up. Even on de-torsion if ovary does not regain its colour immediately it should be conserved, and cystectomy should be performed rather than oophorectomy. Conservative surgery, in the form of ovarian de-torsion can be tried in cases of ischemia but if ovarian necrosis has occurred, then salpingo-oophorectomy is performed as the last resort.
\end{abstract}

Keywords: Conservative surgery, Ovarian torsion, Paediatric age group, Salpingo-oophorectomy

\section{INTRODUCTION}

Ovarian torsion is the fifth most common gynaecologicalsurgical emergency. Women older than 20 years account for almost $70 \%$ of cases. In women aged less than 20years, an estimated incidence of ovarian torsion was 4.9 per $100000 .^{1,2}$ It is commonly associated with underlying ovarian cystic lesion, mass or other abnormality, although torsion of normal ovary may occur, especially in infants and children. Ultrasonography (US) is the primary imaging modality for evaluation of ovarian torsion. US features of ovarian torsion include a unilateral enlarged ovary, uniform peripheral cystic structures, a coexistent mass within the affected ovary, free pelvic fluid, lack of arterial or venous flow may or may not be there, and a twisted vascular pedicle. The presence of flow at colour Doppler imaging does not allow exclusion of torsion but instead suggests that the ovary may be viable, especially if flow is present centrally. Absence of flow in the twisted vascular pedicle may indicate that the ovary is not viable. The role of computed tomography (CT) has expanded, and it is increasingly used in evaluation of abdominal pain. Common CT features of ovarian torsion include an enlarged ovary, uterine deviation to the twisted side, smooth wall thickening of the twisted adnexal cystic mass, fallopian tube thickening, peripheral cystic structures, and ascites. Understanding the imaging 
appearance of ovarian torsion will lead to conservative, ovary-sparing treatment. ${ }^{3}$

\section{CASE REPORT}

This is a case series of 3 pre-pubertal and adolescent girls of 11 years 7 months, 9 years 8 month and 16 years, all admitted in emergency in max smart super speciality hospital on $11^{\text {th }}$ Nov 2017, $3^{\text {rd }}$ July 2018 and $27^{\text {th }}$ uly 2017 respectively.

\section{Case A}

She was 11 years and 7 months of age. Patient presented with chief complaints of pain lower abdomen with difficulty in passing urine for 5 days and had not passed stool for 3 days. She was suffering from recurrent episodes of vomiting, had decrease in appetite and was only on liquids for 3 days.

She was apparently well 5 days back, and suddenly developed pain lower abdomen. For which she consulted paediatrician and was advised analgesics and antispasmodics along with X-Ray and ultrasound whole abdomen. She was given laxatives for loaded large gut, but there was no relief in her symptoms of pain at all. On ultrasound she was diagnosed to have a large left ovarian cyst for which she consulted us in gynae OPD. On repeat Ultrasonography she was diagnosed with torsion of left ovarian cyst with typical features of oedematous ovary with peripherally arranged epithelial cyst and central necrosis.

In her history she was a diagnosed case of single right kidney detected at 3 years of age, on ultrasound done for pain abdomen. She had menarche since Jan'17 and was obese due to her eating habits. Her last menstrual period was on $27^{\text {th }}$ Oct' 17 that is 15 days back and her menstrual cycles were regular. All preoperative investigations done in emergency were within normal limits. Ultrasound showed a lobulated septate structure in left ovary with few small follicles in the surrounding left ovarian tissue, suggestive of complex left ovarian cyst, with possibility of torsion left ovary, with poor delineation of morphology. On doppler flow peak systolic velocity was low suggestive of poor vascularity.

Emergency laparoscopic surgery was done. Left ovarian cyst de-torsion was done followed by left ovarian cystectomy was done. Per operatively uterus, right fallopian tube and right ovary were seen normal. Large left ovarian cyst of 6-7 cm, septate and twisted 3 times on tubo ovarian ligament along with the tube (Figure 1). Detorsion done and left tube and ovarian tissue were seen bluish black inspite of waiting for $>30$ minutes with only slight colour change as indicator of vascularity (Figure 2). Patient relatives were informed that left ovary and tube can have return of vascularity and viability later and left in situ. They were also explained the risk of devitalised left tube and ovary may require repeat surgery for the removal of same and risk of sepsis, later.

Her postoperative period was uneventful and recovered fast, started on liquids orally after 6 hours. She was discharged on 3rd postoperative day.

This patient was followed after one week of surgery for fever or any signs of sepsis or sick feeling, but postoperative recovery was fine.

She was eating well and advised for prolong antibiotic course and HPE reported haemorrhagic ovarian cyst.

She was followed after 3 weeks, 6weeks, 3months and 6 months post surgery by ultrasound doppler study which showed that a part of ovary has started showing follicular activity (Figure 3 and 4).

\section{Case B}

Second case was of morbidly obese pre-pubertal 9 year old girl, presented to us with vague pain lower abdomen for one week and which later subsided. She also was not able to pass stool for 3 days. She was obese due to her eating habits. There was history of hospitalization outside and managed medically on analgesics and laxatives for constipation. Patient was diagnosed case of ovarian torsion and came to our hospital for second opinion and surgery. There was no significant past medical and surgical history. Menarche was not attained. All pre operative investigations were normal. As the patient was young girl with no pain on visit, she was advised for ultrasound lower abdomen and CT scan whole abdomen and pelvis with contrast. The diagnosis of large left sided ovarian cyst of $8.3 \times 6.8 \mathrm{~cm}(114 \mathrm{cc})$ with torsion was confirmed on CT scan. All cancer markers done- before coming to our hospital, CA-125 was 5.83 , beta-HCG was $<1.2$ and alpha fetoprotein was 2.27 and all were normal.

Patient relatives were explained the seriousness and loss of ovarian blood supply and consequences explained and surgical management by laparoscopy was decided.

Per operative findings: - uterus infantile with normal right tube and ovary seen. Left fallopian tube swollen, oedematous and bluish colour with compromised blood supply seen (Figure 5). Left ovarian cyst of $8 \times 5 \mathrm{~cm}$ discolored and adherent to large gut and pouch of Douglas seen by flimsy adhesions, which were separated by blunt dissection. Tube and ovary un-twisted, contained haemorrhagic fluid, which was drained, and cystectomy done (Figure 6) Only slight return of colour noted of left adenexa after 30mins of de-twisting. Both left tube and ovary were left in situ for future return of blood supply. Parents were explained the risk of non-viability of left adenexa. Follow up was done by USG and doppler for return of viability at 1 weeks, (Figure 7) 4 weeks (Figure 8 ) and 12 weeks and gradual increasing blood supply 
(Figure 9) and reduction of oedema noted with no fever or sepsis in later period.

\section{Case C}

Third case is of 16 years admitted in emergency with pain in left side of lower abdomen since 4 days and vomiting for 2 days. She was unable to eat and pass motion for 2 days.

Her last menstrual period was 10 days back with regular previous menstrual cycles. There was no significant past medical and surgical history. On examination her vitals were stable with tender lower abdomen.

All routine investigations done and were normal. Ultrasound showed $5 \times 7 \times 4.5 \mathrm{~cm}$ cystic space occupying lesion with internal septae and loculation with intralesional haemorrhage and torsion. MRI done showed left ovary bulky with a well-defined oval shaped cystic space occupying lesion of $5 \times 7 \mathrm{~cm}$, extending to pouch of Douglas. Patient prepared for emergency laparoscopic surgery for pain and vomiting with ovarian dermoid cyst.

Per operative findings showed left ovarian dermoid cyst of $7 \times 6 \mathrm{~cm}$ size which was discolored, oedematous with 3 turns of torsion of tubo-ovarian mass at infundibulopelvic ligament with bluish black thickened oedematous fallopian tube (Figure 10).

The pedicle de-twisted and soon within 15-20 min there is a return of colour of fallopian tube from blue to pink (Figure 11) Left ovarian dermoid cyst removed and oedematous ovary left in situ for future return of vascularity with prolong course of antibiotics.

All the three patients respond very well to the management and followed by ultrasound doppler at 1,3 and 6 monthly. None of the patient developed fever or any sign of sepsis in 6months follow up post surgery.

\section{RESULTS}

TLC and DLC was normal in all 3 cases hence not a good investigation for diagnosis.

Best modality to diagnose torsion ovary is Ultrasound lower abdomen and pelvis done by experienced operator. In all 3 cases finding on US was bulky ovary with peripherally arranged cystic area which are not follicle but epithelial cysts. Blood supply may or may not be obliterated. Ovary is anteriorly placed.

In case A who presented 5 days after her symptoms there were 3 twists noted per-operatively (Figure 1) and on detorsion ovary did not regain its colour and vascularity (Figure 2). Post op was uneventful. 6 months after detorsion and cystectomy return of follicular activity and vascularity noted in ultrasound (Figure 4) (Table 1).

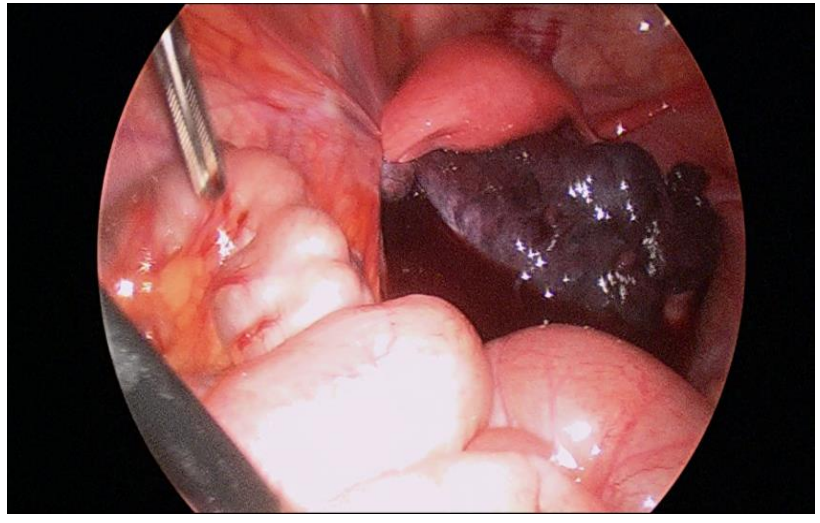

Figure 1: 11 years old girl-Torsion of left tubo ovarian ligament with bluish black oedematous adnexa prior to detorsion.

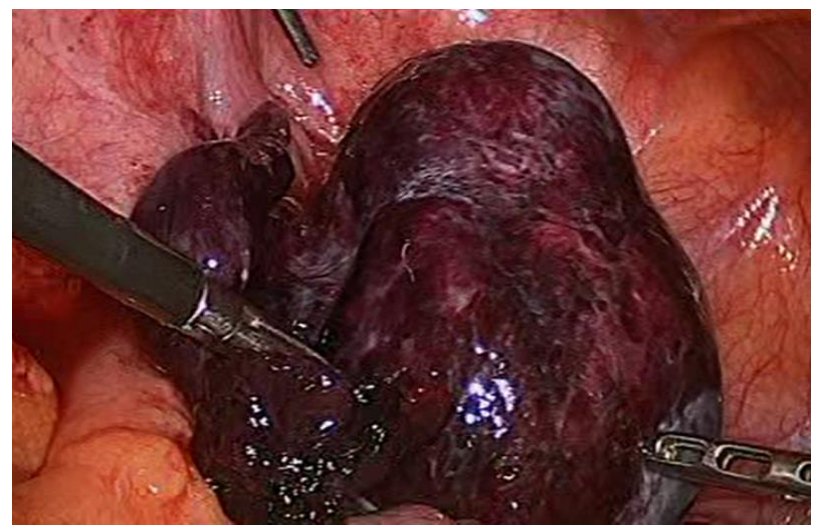

Figure 2: Return of mild vascularity noted after detorsion by patchy changes in colour noted after 4045 minutes (Case A).

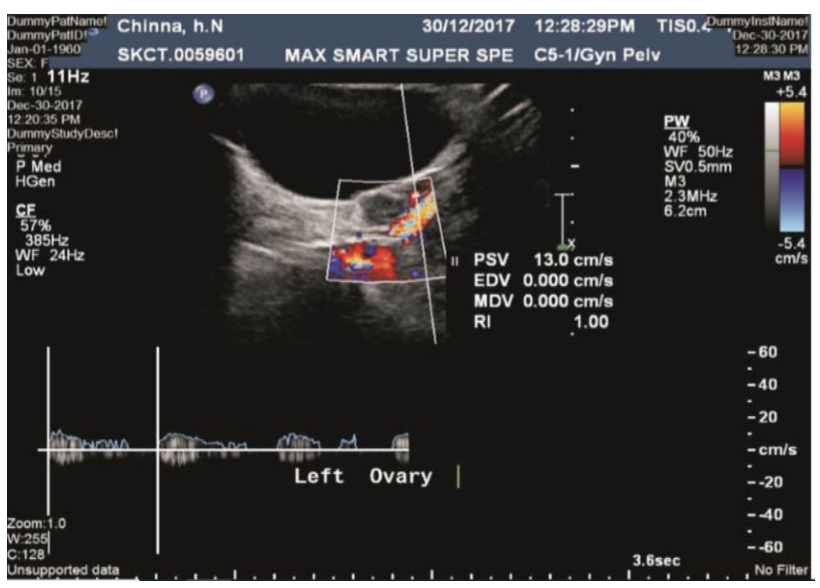

Figure 3: 11 years of Left ovary after cystectomy, still bulky and oedematous with few follicles and showing minimal blood flow in ovary after 1 month follow up.

In case $B$ who presented to us after 7days of her symptoms there was 2.5 twists seen per-operatively (Figure 5) and on detorsion, ovary did not regain its colour and vascularity (Figure 6). Cystectomy was done and post op was uneventful. 3 months after detorsion and 
cystectomy there is mild return of blood supply and small left ovary seen clearly in ultrasound (Figure 9) (Table 1).

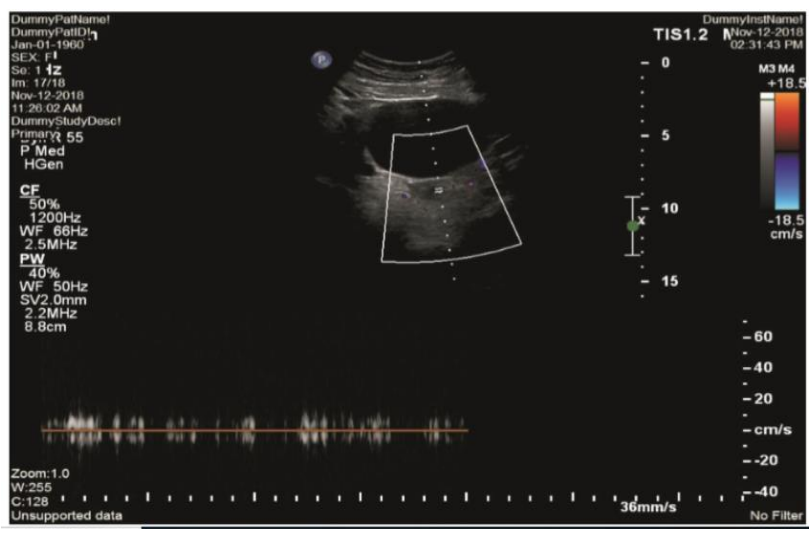

Figure 4: USG marked improvement in vascularity and follicle in 6 months follow up (Case A).

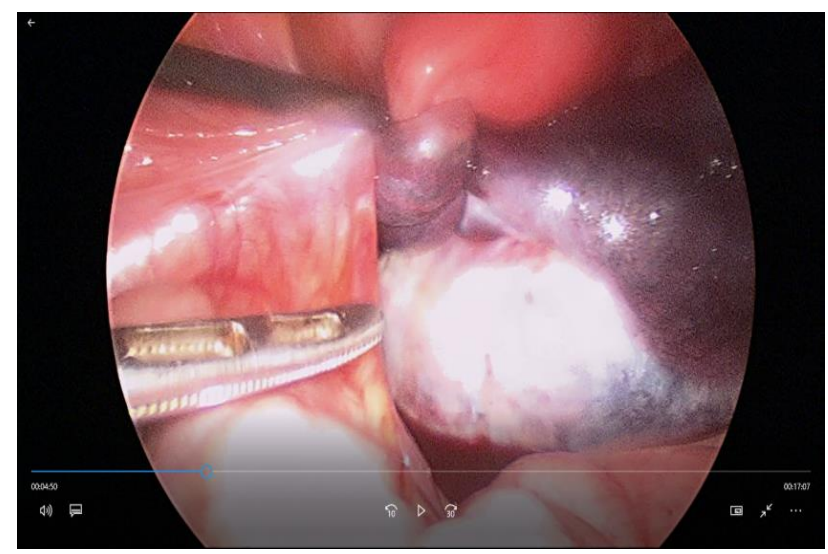

Figure 5: 9 years prepubertal girl- Torsion of left tubo-ovarian pedicle with bluish black adenexa prior to de-torsion.

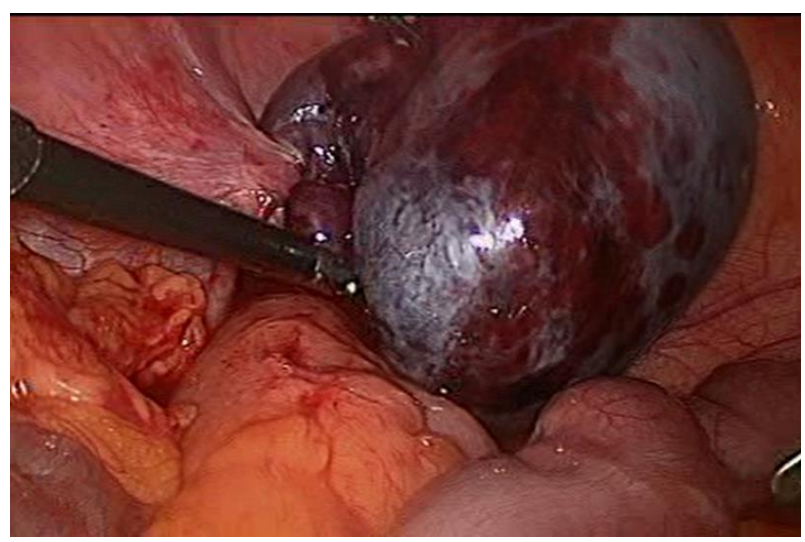

Figure 6: Large left ovarian cyst with bluish black oedematous tube after de-torsion (Case B).

In case $\mathrm{C}$ who presented 3 days after her symptoms there was 3 twists noted per-operatively and on detorsion ovary regain its colour and vascularity in 30min completely (Figure 10 and 11). This patient was not followed by postoperative ultrasound for vascularity as return of blood supply seen per-operatively (Table 1).

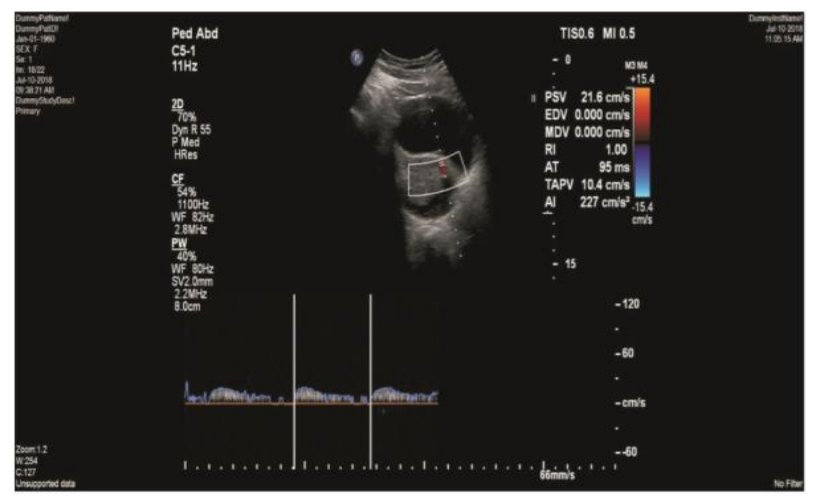

Figure 7: 1 week postoperatively: 9 years old girl-USG image showing a heterogenous echogenicity structure of 3.6x 2.8x $2.0 \mathrm{~cm} \sim 11.3 \mathrm{cc}$ in POD, consistent with left ovary with mild high resistance flow is seen lateral to it.

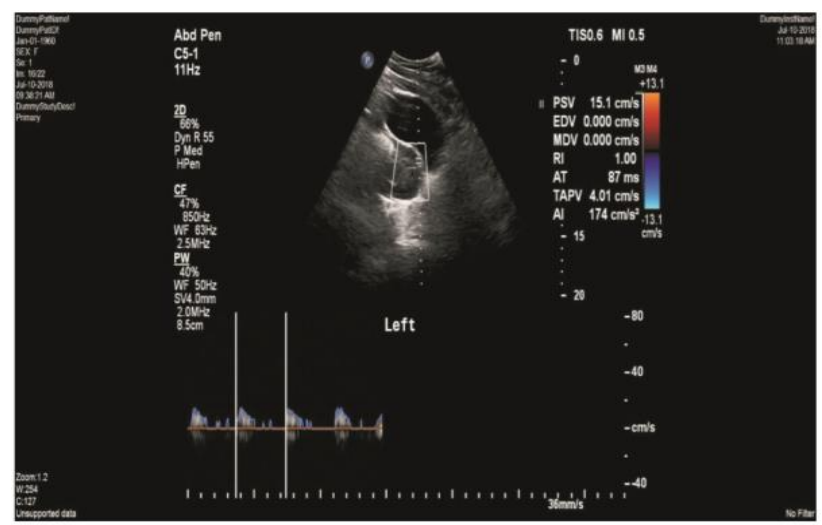

Figure 8: 1 month follow up USG Left ovary is bulky, seen in POD (10.7cc) with mild peripheral vascularity with high resistance flow is seen. RI $1.0, P S V 23 \mathrm{~cm} / \mathrm{s}$ (Case B).

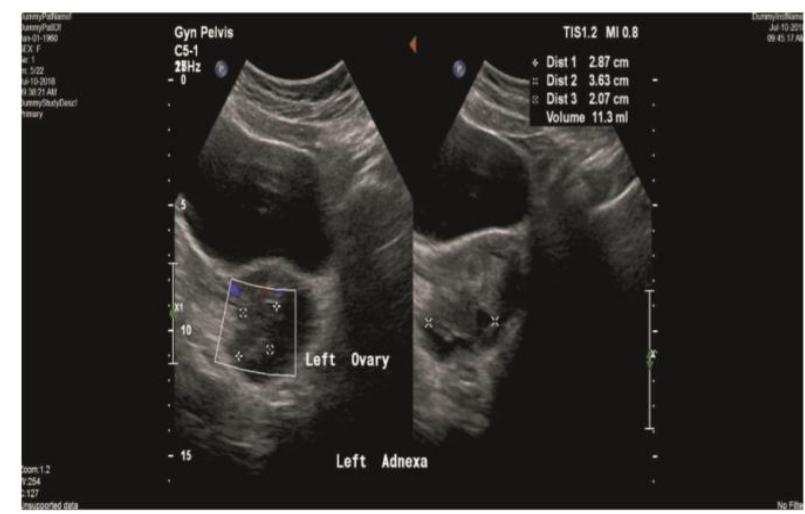

Figure 9: Ovary viable in 3 months follow up and very minimal vascularity with left ovary poorly visualized as small soft tissue in left adnexa $(1.3 \mathrm{cc})$ on ultrasound (Case B). 
Table 1: Summary of results of duration of symptoms operative findings and post-surgery US findings.

\begin{tabular}{|c|c|c|c|}
\hline $\begin{array}{l}\text { Patient } \\
\text { detail } \\
\text { (age) }\end{array}$ & $\begin{array}{l}\text { Duration } \\
\text { of } \\
\text { symptoms } \\
\text { (days) }\end{array}$ & $\begin{array}{l}\text { Operative } \\
\text { findings }\end{array}$ & $\begin{array}{l}\text { Return of } \\
\text { ovarian } \\
\text { vascularity }\end{array}$ \\
\hline $\begin{array}{l}\text { Case A } \\
(11 \\
\text { years })\end{array}$ & 5 & $\begin{array}{l}3 \text { twists seen } \\
\text { in left tube } \\
\text { and ovary. } \\
\text { Colour did } \\
\text { not return to } \\
\text { normal after } \\
\text { de-torsion } \\
\text { even after } \\
30 \text { minutes }\end{array}$ & $\begin{array}{l}\text { On Ultrasound } \\
\text { follow up } \\
\text { After } 6 \\
\text { months, return } \\
\text { of vascularity } \\
\text { with follicular } \\
\text { activity noted }\end{array}$ \\
\hline $\begin{array}{l}\text { Case B } \\
(9 \\
\text { years })\end{array}$ & 7 & $\begin{array}{l}2.5 \text { twists } \\
\text { seen in left } \\
\text { adnexa. } \\
\text { Colour } \\
\text { change seen } \\
\text { very } \\
\text { minimal }\end{array}$ & $\begin{array}{l}\text { Minimal } \\
\text { return of } \\
\text { ovarian } \\
\text { vascularity } \\
\text { with reduced } \\
\text { ovarian } \\
\text { volume noted } \\
\text { after } 3 \text { months }\end{array}$ \\
\hline $\begin{array}{l}\text { Case C } \\
(16 \\
\text { years })\end{array}$ & 3 & $\begin{array}{l}3 \text { twist seen } \\
\text { with } \\
\text { oedema. } \\
\text { Colour and } \\
\text { vascularity } \\
\text { returned } \\
\text { immediately } \\
\text { after de- } \\
\text { torsion }\end{array}$ & $\begin{array}{l}\text { Return of } \\
\text { ovarian } \\
\text { vascularity to } \\
\text { normal thus } \\
\text { no follow up } \\
\text { with USG } \\
\text { done and } \\
\text { patient } \\
\text { asymptomatic. }\end{array}$ \\
\hline
\end{tabular}

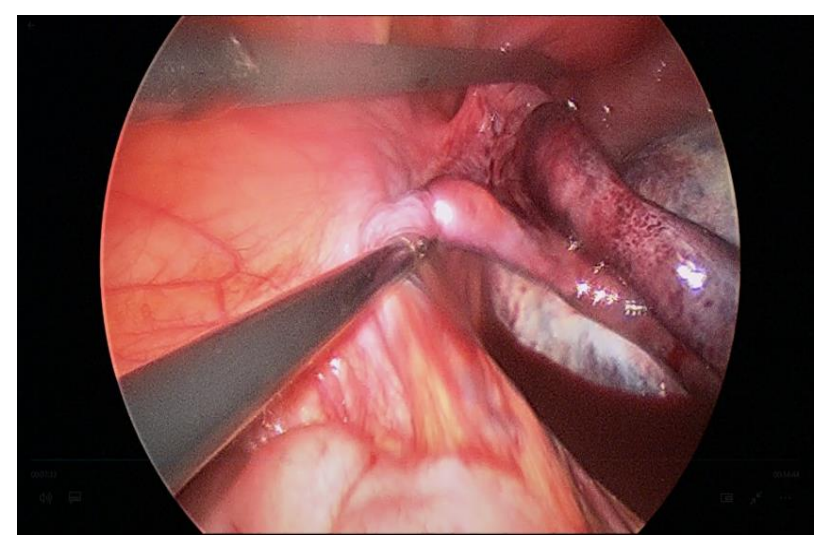

Figure 10: Mild return of colour noted after de-torsion (Case $\mathrm{C}$ ).

None of the above cases developed fever or any pelvic infection or required repeat surgery in follow up till 6 months after leaving detorted ovary with visible compromised blood supply. These patients were given prophylactic prolonged antibiotic treatment to avoid any pelvic infection later if any necrosis developed. These all cases showed return of blood supply and ovarian activity on ultrasound done 3-6 months later.

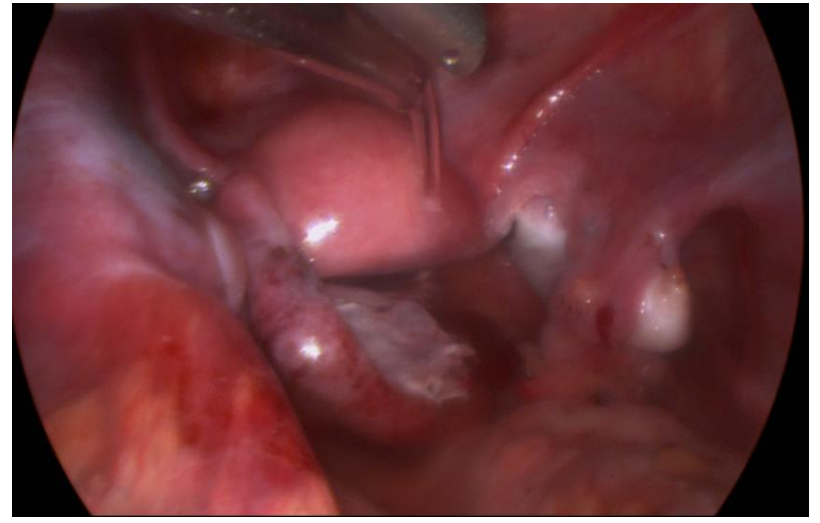

Figure 11: Complete return of colour and vascularity after de-torsion after $30 \mathrm{~min}$ (Case $\mathrm{C}$ ).

Diagnosis of ovarian torsion requires clinician awareness and a high degree of suspicion. Conservative surgery, in the form of ovarian de-torsion can be tried and one should try to do cystectomy to conserve ovary in these young girls. In case ovary after de-torsion has become friable and cystectomy is not possible then salpingooophorectomy should be performed as the last resort. ${ }^{4}$

\section{DISCUSSION}

Ovarian torsion is uncommon but occurs in all ages and is typically associated with normal ovaries or benign lesions. Improved awareness of the epidemiology may help to guide management. Ongoing analysis is being done to identify factors that are associated with successful conservative management. ${ }^{5}$

Ovarian torsion in childhood and adolescence is a rare entity. Traditionally, treatment is oophorectomy. The rationale for such operation in the past was based on the following condition: (1) the blue black ovaries are nonviable; (2)a mere detorsion would trigger possible thromboembolic phenomenon. ${ }^{6}$ The aim of this study was to evaluate ovarian outcome and to propose a decisionmaking protocol for suspected ovarian torsion.

Ovarian torsion, previously treated by laparotomy and oophorectomy, often can be managed by laparoscopically. ${ }^{7,8}$ Even if there is apparent necrosis, the adenexa can be untwisted, usually with preservation of normal ovarian function. ${ }^{9,10}$

Spinelli C et al, discussed the surgical treatment for ovarian torsion in children and adolescents with a focus on the procedures of adenexal conservation surgery and its frequency in follow up for 10years (2000-2010) and a statistical analysis which shows a slow increase in conservative surgery from $28-45 \%{ }^{11}$

Lasso Betancor $\mathrm{CE}$ et al, studied ovarian torsion retrospectively (from May 2010 to May 2013), long term follow up of the bluish black ovary after laparoscopic detorsion. ${ }^{12}$ During the first 6 months the follow up 
ultrasound showed good results. However the long term outcome evidenced one ovary atrophied and 2 oophorectomies due to recurrent adenexal torsion.

Galinier P et al, reported 45 cases between January 1986 and December 2007, 45 ovarian torsion cases in 40 girls were operated on. In all the cases, when the ovary was preserved, patients were clinically and ultrasonographically followed up for several months. ${ }^{13}$ Median age was 11 years. Median delay between the first symptoms and surgical procedure was 3 days. $^{5}$ Conservative management was performed in 26 cases. At follow-up, 17 ovaries were follicular, 7 being blackbluish during surgery.

Median age in our study was 12 years and interval between onset of symptoms and surgery was 5 days. In our study all the cases have pain abdomen followed by unable to pass stool and loss of appetite. All the cases were treated conservatively by laparoscopic ovarian cystectomy with retention of bluish black ovary with no adverse post-operative consequences with return of ovarian vascularity noted in follow-up.

Acute ovarian torsion accounts for up to $2.7 \%$ of all cases with acute onset lower abdominal pain in children accompanied by vomiting and is the most common complication of ovarian tumors in children with an incidence ranging from 3-16\%. Pain can be characterized as constant or colicky, but unlike with appendicitis, does not typically migrate. Ultrasound is the most useful initial diagnostic modality, but the absence of flow on Doppler imaging is not always present. Conservative management with de-torsion and ophoropexy is recommended. ${ }^{14}$ Torsion is more common on right side (3:2), possibly either because of the sigmoid colon limiting the movement on left side or a hypermobile cecum on the right that is more permissive to movement and could also be due to longer right ovarian ligament. ${ }^{15,16}$ The features of ovarian torsion includes a unilateral enlarged ovary, uniform peripheral cystic structures, a coexistent mass within the affected ovary, free pelvic fluid, lack of arterial or venous flow, and a twisted vascular pedicle. The presence of flow at colour Doppler imaging does not reliably exclude torsion but instead suggest that the ovary may be viable..$^{5}$ Data about the characteristics of prepubertal and adolescent girls with ovarian torsion are limited.

A study by Styer and Laufer advocated that only detorsion is recommended to be performed in the" blue black" ovaries. Cystectomy should be carried out probably six weeks later if the cyst persists. Technically it would be more difficult to enucleate the cyst from the gangrenous ovarian tissue and secure the hemostasis. ${ }^{17}$ Laparoscopic conservative management with untwisting the ovary, allows that macroscopically nonviable ovaries could be recovered. However, an exhaustive and longterm follow-up is required to confirm the outcome. ${ }^{18}$
Funding: No funding sources

Conflict of interest: None declared

Ethical approval: Not required

\section{REFERENCES}

1. Piper HG, Oltmann SC, Xu L, Adusumilli S, Fischer AC. Ovarian torsion: diagnosis of inclusion mandates earlier intervention. J Pediatr Surg. 2012;47(11):2071-6.

2. Guthrie BD, Adler MD, Powell EC. Incidence and trends of pediatric ovarian torsion in the United States. 2000-2006. Pediatrics. 2010;125(3):532-8.

3. Hannah CC, Shweta B, Vikram SD. Pearls and Pitfalls in Diagnosis of Ovarian Torsion. Radiographics. 2008;28(5):1355-68.

4. Mishra V, Hokabaj S, Roy P, Aggarwal R, Vyas B, Mehta N. Case series of paediatric adnexal torsion: rare yet urgent entity. Int J Reprod Contracept Obstet Gynecol. 2017;6(1):315-9.

5. Bridgette DG, Mark DA, Elizabeth CP. Incidence and Trends of Pediatric Ovarian Torsion Hospitalizations in the United States, 2000-2006. Pediatrics. 2010;125(3):532-8.

6. Azurah AG, Zainol ZW, Zainuddin AA, Lim PS, Sulaiman AS, Ng BK. Update on the management of ovarian torsion in children and adolescents. World J Pediatr. 2015;11(1):35-40.

7. Mage G, Canis M, Manhes H, Pouly JL, Bruhat MA. Laparoscopic management of adenexal torsion. A review of 35 cases. J Reprod Med. 1989;34(8):520-4.

8. Vancaillie T, Schmidt EH. Recovery of ovarian function after laparoscopic treatment of acute adnexal torsion. A case reports. J Reprod Med. 1987;32(7):561-2.

9. Galinier P, Carfagna L, Delsol M, Ballouhey Q, Lemasson F, Le Mandat A, et al. Ovarian torsion. Management. Pediatr surg. 2009;44(9):1759-65.

10. Cohen SB, Oelsner G, Seidman DS, et al. Laparoscopic detorsion allows sparing of the twisted ischaemic adenexa. J Am Assoc Gynecol Laparosc. 1999;6(2):139-43.

11. Spinelli C, Buti I, Pucci V, Liserre J, Alberti E, Nencini L, et al. Adnexal torsion in children and adolescents: new trends to conservative surgical approach-our experience and review of literature. Gynecol Endocrinol. 2013;29(1):54-8.

12. Lasso CB, Garrido JP, Murcia FP, Granero RC, Vargas VC, Paredes RE. Ovarian torsion. long-term follow-up of the black-bluish ovary after laparoscopic detorsion. Cir Pediatr. 2014;27(1):2630.

13. Galinier P, Carfagna L, Delsol M, Ballouhey Q, Lemasson F, Le Mandat A, et al. Ovarian torsion. Management and ovarian prognosis: a report of 45 cases. J Pediatr Surg. 2009;44(9):1759-65.

14. Poonai N, Poonai C, Lim R, Lynch T. Pediatric ovarian torsion: case series and review of the literature. Canadian J Surg. 2013;56(2):103-8. 
15. Jennifer Eng-Lunt, Heather A, Jahn A. Pediatric and adolescent ovarian torsion. ACEP News. 2014;47(3):11472-76.

16. Cass DL, Hawkins E, Brandt ML, Chintagumpala M, Bloss RS, Milewicz AL, et al. Surgery for ovarian masses in infants, children and adolescents: 102 consecutive patients treated in 15 year period. J Pediatr Surg. 2001;36(5):693-9.

17. Styer AK, Laufer MR. Ovarian bivalving after detorsion. Fertil Steril. 2002;77(5):1053-5.
18. Mishra V, Hokabaj S, Roy P, Aggarwal R, Vyas B, Mehta N. Case series of paediatric adnexal torsion: rare yet urgent entity. Int J Reprod Contracept Obstet Gynecol. 2017;6(1):315-9.

Cite this article as: Bhandari $\mathrm{R}$, Khemani $\mathrm{M}$,

Mustafa A. Cases of management of paediatric tuboovarian torsion. Int J Reprod Contracept Obstet Gynecol 2019;8:2888-94. 